\section{Endoscopic extraction of a fish bone with a Foley catheter after endovascular stent graft placement for penetrating aortoesophageal injury}

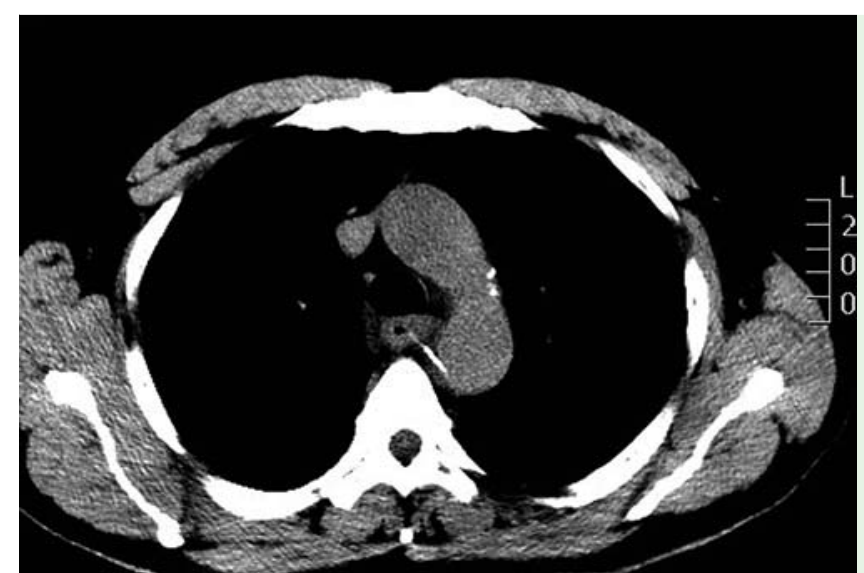

Fig. 1 Computed tomographic scan showing a foreign body penetrating through the esophagus into the thoracic aorta in a 55-year-old man presenting with retrosternal pain and odynophagia.
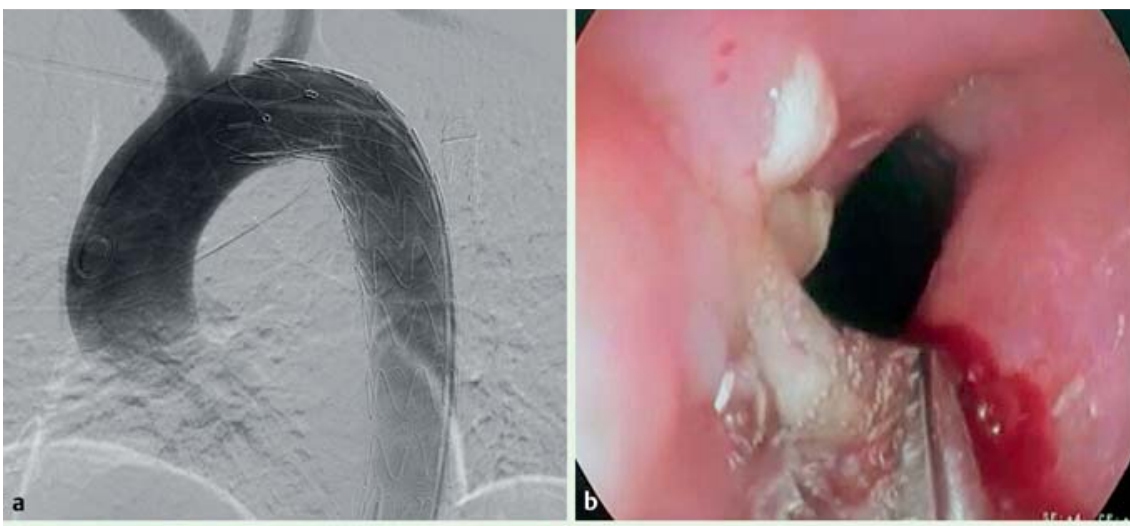

c.

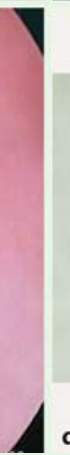

Fig. 2 a Intraoperative aortography showing no extravasation of contrast agent after stent graft placement. $\mathbf{b}$ Both ends of the bone are impacted in the esophagus close to the second narrowing. $\mathbf{c}$ The catheter balloon dilating the esophageal lumen. d A 40-mm-long sharp bone with two pointed ends.

A 55-year-old man was admitted with retrosternal pain and odynophagia of 5 days' duration. The patient had ingested a fish bone just before the onset of symptoms. He had a 4-year history of coronary artery disease and myocardial infarction. Computed tomography showed a foreign body penetrating through the esophagus into the thoracic aorta ( $\bullet$ Fig.1). No signs of mediastinitis were identified.

After a multidisciplinary discussion, endoscopic bone removal was planned with simultaneous endovascular stent graft placement. A $34 \times 180-\mathrm{mm}$ stent graft was implanted in the thoracic aorta via the femoral artery ( $\bullet$ Fig. 2 a). Gastro- intestinal endoscopy revealed a fish bone lodged in the esophagus at $250 \mathrm{~mm}$ from the incisors. Both ends were impacted in the esophagus, with a short segment in the lumen ( $\bullet$ Fig. 2 b). Despite numerous attempts at removal with a foreign body forceps, neither end could be separated from the esophageal wall because of the narrow space. It was impossible to cut the hard bone endoscopically.

As a last attempt before surgery, a $14 \mathrm{Fr}$ Foley catheter was introduced beyond the bone. The catheter was inflated with $15 \mathrm{~mL}$ of normal saline, dilating the portion of the esophageal lumen distal to the bone ( Fig. $2 \mathrm{c}$ ). The bone, which was almost $40 \mathrm{~mm}$ long with two pointed ends ( $\bullet$ Fig. 2 d), was then separated and extracted. A nasojejunal feeding tube was placed. The patient's postoperative recovery was uneventful ( $\bullet$ Fig.3).

Several instruments have been used to retrieve foreign bodies, including forceps, polypectomy snare, and Roth basket. A major disadvantage of these tools is their limited ability to overcome anatomical obstacles [1]. A Foley catheter is usually used under fluoroscopic guidance to remove blunt foreign bodies from children [2]. In our case, we used this simple and primitive type of catheter to dilate the esophagus before bone removal. The use of a Foley catheter is an option for extracting sharp objects with two ends impacted in the esophagus.

\section{Endoscopy_UCTN_Code_TTT_1AO_2AL}

\section{Competing interests: None}

\section{Xiangjiu Ding ${ }^{1}$, Qingbo Su ${ }^{1}$, Ning Zhong' ${ }^{2}$, Jianjun Jiang ${ }^{1}$}

${ }^{1}$ Department of Vascular Surgery, Qilu Hospital, Shandong University, Jinan, China

${ }^{2}$ Department of Gastroenterology, Qilu Hospital, Shandong University, Jinan, China

\section{References}

1 Munoz JC, Habashi S, Corregidor AM et al. Extraction of hollow gastric foreign bodies by flexible upper endoscopy assisted by a through-the-scope balloon catheter for anchoring. Gastrointest Endosc 2008; 67: $519-521$

2 Bigler FC. The use of a Foley catheter for removal of blunt foreign bodies from the esophagus. J Thorac Cardiovasc Surg 1966; 51: $759-760$ 


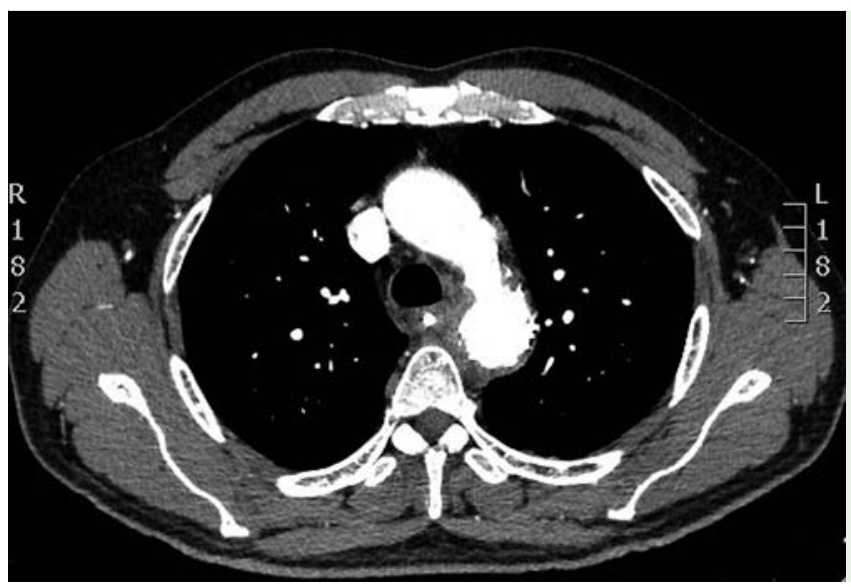

Fig. 3 Computed tomographic scan before nasojejunal tube removal showing no paraesophageal collection or mediastinitis.

\section{Bibliography}

DOI http://dx.doi.org/

10.1055/s-0034-1392615

Endoscopy 2015; 47: E406-E407

(c) Georg Thieme Verlag KG

Stuttgart · New York

ISSN 0013-726X

\section{Corresponding author}

\section{Jianjun Jiang, MD}

Department of Vascular Surgery Qilu Hospital

Shandong University

107, Wenhua Xi Road

Jinan

250012, P.R. China

Fax: +86-531-8692-0598

qlxgwklt@163.com 